\title{
НАУЧНО-ТЕХНИЧЕСКИЙ ФОРУМ «ТЕХНОЛОГИИ ОБРАБОТКИ МАТЕРИАЛОВ, РОБОТОТЕХНИКА И «ИНДУСТРИЯ 4.0»
}

Одной из важных частей деловой программы выставки «Металлообработка-2019», прошедшей с 27 по 30 мая в Москве в ЦВК «Экспоцентр», стал 9-й международный научно-технический форум «Технологии обработки материалов, робототехника и «Индустрия 4.0». Форум открылся пленарным заседанием, тема которого была обозначена как «Развитие потенциала промышленности России. Вклад российского станкостроения в реализацию национальных проектов». Модератором выступил заместитель председателя Коллегии Военно-промышленной комиссии РФ Олег Бочкарев.

Открыл заседание заместитель председателя Комитета Государственной Думы по экономической политике, промышленности, инновационному развитию и предпринимательству Денис Кравченко, который в своем выступлении привел данные о текущем состоянии и развитии российского станкостроения. По его словам, технологическое отставание нашей страны в области станкостроения за последние 10 лет сократилось. Российские производители и структурные «мозговые центры» приступили к освоению наукоемких компонентных узлов, наращиванию собственных мощностей. Ключевой тренд в станкостроении - медленное, но верное

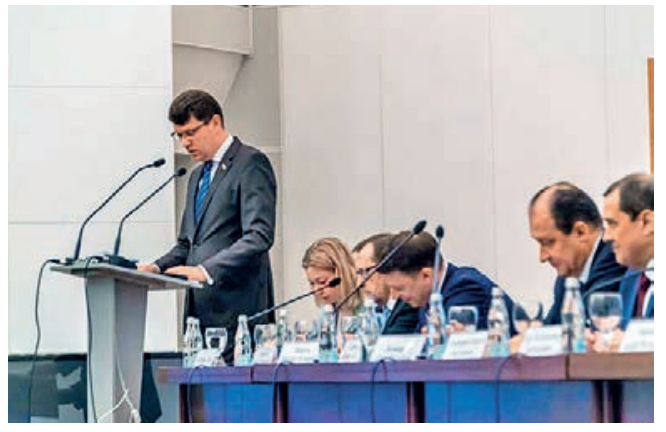

укрепление позиций российских производителей комплектующих. Вся отрасль показывает позитивную динамику, однако зависимость от импорта еще крайне высока, сказал депутат.

Денис Кравченко также сообщил, что если в 2014 году доля импорта в станкостроительном парке России достигала $87 \%$, то три года спустя за счет создания собственных производств эту долю удалось сократить до $70 \%$.

Анализ ситуации в российском станкостроении развил в своем выступлении директор Департамента станкостроения и инвестиционного машиностроения Минпромторга России Михаил Иванов.

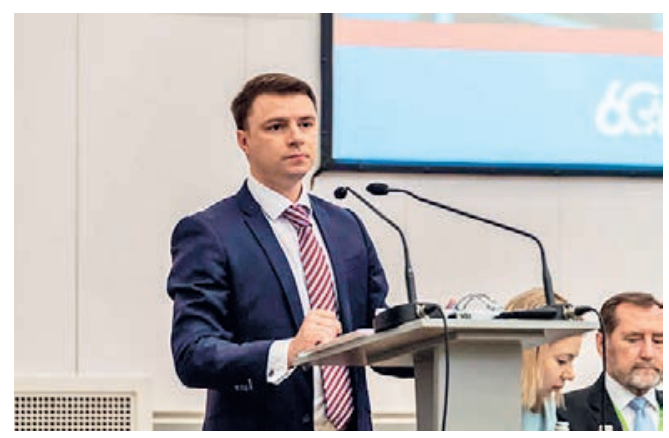

По его словам, с 2014 года отрасль живет решением задач импортозамещения. В правительстве был принят соответствующий план, сформулированный в Распоряжении Правительства РФ от 30 сентября 2014 года № 1936-р по импортозамещению в различных отраслях. В результате, по итогам 2018 года доля российской продукции на рынке составила 34\%. В 2018 году рост производства металлорежущих станков в стране составил около 5\%, а объем реализации 15 млрд руб., рост производства инструмента $-15 \%$, а выручка - 18 млрд руб. 
При этом отрасль в 2018 году получила господдержку по линии Министерства промышленности и торговли, которая по итогам года достигла почти 1 млрд руб. В основном это были займы ФРП, а также специальные инструменты, которые работают на различных стадиях жизненного цикла промышленной продукции: это и поддержка стадии опытно-конструкторских разработок, и стадия вывода продукции на рынок - инструмент поддержки пилотных партий продукции.

По итогам прошедшей пятилетки, по мнению Михаила Иванова, как представителя регулятора, в области промышленной политики сделано практически все необходимое. Реализовано многое и в части решения регуляторных задач. В частности отрегулированы закупки государственных заказчиков в рамках Федерального закона № 44-Ф3, настроена регуляторика закупок компаниями с госучастием и госкомпаний в рамках Федерального закона № 223-Ф3, которым установлено $15 \%$-ное ценовое преимущество. В соответствии с Постановлением Правительства РФ от 16 сентября 2016 года № 925 появился механизм правительственной комиссии по импортозамещению, заработал целый ряд инструментов ограничительного характера, а также механизмы поддержки. За счет этого удалось добиться в некоторых отраслях качественного скачка в части доступа российских компаний на рынок.

Сегодня взят курс на реализацию национальных проектов, в рамках которого основная задача состоит в выводе на рынок линейки качественных конкурентоспособных продуктов. Поэтому основной национальный проект, который ведет Министерство промышленности и торговли, называется «О международной кооперации и экспорте» и связан с реализацией корпоративных программ повышения конкурентоспособности (КППК). Поставлена амбициозная задача: к 2024 году увеличить экспорт продукции отечественного машиностроения с 33 до 60 млрд долл.

В прошлом году экспорт продукции станкостроения увеличился на $16 \%$, при этом с учетом низкой базы пока стоит говорить об этой цифре лишь как о результате волатильности рынка, но в дальнейшем это должно стать трендом.

В части развития экспорта станкостроительной продукции была проделана работа по анализу возможностей российских производителей, по ее результатам подготовлена своего рода «памятка» для российских станкостроителей и экспортеров. В ней проанализированы перспективные регионы, в том числе страны традиционного присутствия (страны СНГ), а также крупнейшие мировые рынки, такие как Германия, Индия, США, добавлены и новые рынки - Вьетнам, Куба, Мексика и ряд других стран.
Конечно, нельзя рассматривать реализацию национального проекта по расширению экспорта вне связи с ситуацией, которая сегодня складывается на мировом рынке станкостроения, который с 2011 года сократился к 2018 году на 19\%. А азиатский рынок, который сегодня составляет половину мирового рынка, упал на 52\% за тот же период. Российские компании работают в складывающихся условиях и должны учитывать их при составлении программ экспорта оборудования.

Помимо странового сегмента, проведен анализ номенклатурных ниш, в которых наши станкостроители могут быть востребованы. Речь прежде всего идет об относительно новых направлениях - аддитивном оборудовании, гибридных станках, высокоточных 5-осевых обрабатывающих центрах, системах гибкого производства, цифровизации и т.д.

С февраля текущего года заработал основной инструмент поддержки экспорта - Постановление Правительства РФ № 191, которым определены принципы отбора участников, реализующих КППК, и порядок заключения с ними соглашений о предоставлении субсидий в рамках банковского кредитования. Отбор получателей субсидии по постановлению завершился 15 июня 2019 года.

Компании, прошедшие отбор и представившие планы своего развития на шестилетку, получат возможность привлечь на коммерческом рынке финансирование со скидкой 4,5\% от текущих ставок коммерческих банков. То есть доступность денег в рублях достигнет уровня $6 \%$, а в валюте $4-4,5 \%$, это достаточно хорошее подспорье для развития производства или торгового финансирования. Для станкостроительной отрасли лимит на 6 лет определен в 6 млрд руб., а это примерно 150 млрд руб. доступных кредитов, которыми отрасль может воспользоваться.

Если говорить о других национальных проектах, то у станкостроителей есть возможность прямо или косвенно принять участие в проектах по всем 12 направлениям.

Михаил Иванов отметил, что поскольку форум посвящен в том числе теме «Индустрии 4.0», нельзя не упомянуть о вопросе цифровизации. Сегодня Минпромторг России развивает государственную информационную систему промышленности, это цифровая артерия, которая связывает процессы, происходящие внутри отрасли, взаимодействие с потребителями. Создан электронный каталог, который насчитывает свыше 326 тыс. видов промышленной продукции, которые производят наши отрасли. Это работает в единой среде, например, с площадкой «Газпромбанка», пользователи имеют возможность заключать контракты на поставку продукции в цифровой среде. Развитие этой системы подразумевает решение огромного количества 
задач, в том числе задачу консолидации спроса на материалы и комплектующие, укрупнение лотов, работу с поставщиками ресурсной базы для станкостроителей. Эта работа будет продолжаться.

В рамках ФРП создана программа «Цифровизация промышленности», которая предусматривает льготное кредитование проектов по оцифровке производства. На сегодня только 10\% компаний удовлетворяют критериям цифрового производства, еще $40 \%$ готовят программы цифровизации. На изученных кейсах определены конкретные выгоды.

Затем участники заседания перешли к обсуждению механизмов государственного стимулирования и эффективности мер господдержки отечественных станкостроительных предприятий, их роль в реализации национальных проектов, в переходе машиностроения к цифровому производству и создании технологического задела для развития экспортного потенциала отрасли и другие важные вопросы.

В кратком выступлении первый заместитель директора Фонда развития промышленности Андрей Манойло отметил, что в ФРП можно получить дешевые длинные деньги на развитие станкостроительного производства по понятной прозрачной процедуре. По итогам пяти лет работы ФРП профинансировано 411 проектов, соответственно 411 заемщиков получили решения о субсидиях суммарно на 91,9 млрд руб. Главный результат - 137 открытых новых производств. В том числе в станкоинструментальной отрасли реализовано 19 проектов. Базовые принципы работы ФРП - софинансирование (50:50 или $80: 20)$, целевое назначение, возвратность. Ставка финансирования составила 1,3 или 5\%, в зависимости от проекта. Средняя сумма займа - 250 млн руб. Стоит отметить две программы - станкостроение и цифровизация.

Генеральный директор Российского технологического агентства Владимир Пастухов говорил о том, что при работе в рамках Постановления Правительства РФ № 239 о запрете приобретения иностранных станков при наличии российских аналогов необходима экспертиза от Ассоциации «Станкоинструмент».

Другим важным для станкоинструментальной отрасли направлением деятельности агентства является участие в работе в рамках комиссии по импортозамещению - необходим детальный и сущностный анализ того, действительно ли есть российские аналоги иностранных станков, либо необходимо что-либо изменить в ТЗ заказчика.

Еще одно направление в рамках работы по национальным проектам - оценка спроса на инвестиционную продукцию, который по оценке за шесть лет составит 6 трлн руб. и уже сейчас на $50 \%$ может быть удовлетворен российскими производителями.

Важным подспорьем для станкостроителей является то, что Президент РФ поддержал предложение о 15\%-ной ценовой преференции при закупках в рамках национальных проектов. Также прорабатывается вопрос о дополнительных мерах защиты рынка по конкретной номенклатуре: либо о полном запрете закупок иностранного производителя, либо о его закрытии по принципу «третий лишний». Также на национальный проект «Международная кооперация и экспорт» выделено 426 млн руб. на субсидирование процентной ставки, из них 30\% - это инвестиционные кредиты.

Директор Института машиноведения РАН Виктор Глазунов в своем выступлении рассказал о том, что Институт был головным в проекте КПНИ (Комплексные планы научных исследований), поэтому хорошо знаком с проблематикой станкостроения применительно к работе РАН. К сожалению, с 2013 по 2020 год в планах РАН слово «станкостроение» ни разу не упоминается, хотя сопряженная тематика присутствует в исследованиях различных институтов. Можно выделить четыре направления: новые механизмы и новая кинематика, диагностика, новые материалы (трение и износ) и новые технологии. По каждому из этих направлений есть наработки.

Управляющий директор компании «ЦИФРА». Павел Растопшин поднял вопрос о том, насколько цифровизация может стать драйвером роста станкостроения и насколько велик потенциал экспорта.

Сегодня происходят кардинальные изменения в мировом станкостроении, при этом производительность труда в российском станкостроении в 10 раз ниже, чем в Германии, и в 30 раз ниже, чем в Японии. В то же время мировые лидеры станкостроения увеличивают долю ПО в выручке (ПО + сервис до 30\%).

Значительного роста производительности можно добиться при внедрении MES-систем (системы управления производственными процессами) за счет сокращения простоев и затрат на инструмент, введения сквозной прослеживаемости производства

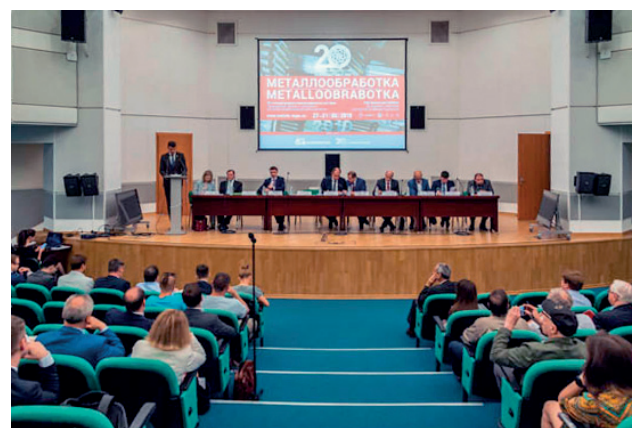
и повышения качества продукции. В этой области Россия сейчас является лидером - к MESсистемам подключено 8 тыс. станков на 150 предприятиях Ростеха, Концерна «АлмазАнтей», КТРВ и др. Есть примеры внедрения системы с подключением 500 станков на одном заводе и более 1000 станков на предприятиях одного холдинга. 
Российские разработчики опережают других мировых производителей подобного софта. Российское ПО уже широко поставляется в страны АТР, Индию, Восточную Европу и др. Ряд позиций оборудования, в том числе 5-осевые ОЦ, можно сейчас не импортозамещать, а продавать по всему миру с российским ПО в силу ценовой конкурентоспособности из-за низких затрат в станкостроении.

Интерес участников вызвало выступление доктора Манфреда Либля, Уполномоченного представителя департамента содействия экономике федеральной земли Саксония (Германия) по развитию сотрудничества с Россией и странами СНГ. Он остановился на важных технологических тенденциях в отрасли, которые приведены в отчете союза станкостроителей Германии за 2017 год:

$\rightarrow$ реализация «Индустрии 4.0», включая интеграцию робототехники;

$\rightarrow$ высокопроизводительные процессы обработки, обработка закаленных деталей, сухая обработка и применение минимального количества смазочных веществ;

$\rightarrow$ микрообработка для производства миниатюризированных заготовок;

$\rightarrow$ высокопроизводительные лазерные технологии, оборудование и источники луча;

$\rightarrow$ комплексная обработка и сокращение технологической цепочки путем интеграции различных операций в одном станке;

$\rightarrow$ адитивное производство и гибридные процессы;

$\rightarrow$ более эффективные технологии обработки волокнистых композитов;

$\rightarrow$ инновационные системы управления с функцией объединения в сеть и дистанционной диагностики;

$\rightarrow$ обнаружение неисправностей вплоть до уровня периферийных приборов;

$\rightarrow$ сквозное применение технологий CAX (совокупность систем автоматизированного проектирования - CAПР, или CAD- CAE- CAM-системы) от цифровой модели до готового изделия;

$\rightarrow$ инструменты для моделирования и работы с виртуальной реальностью для проектирования и разработки эффективных производственных систем;

$\rightarrow$ повышение энергоэффективности и применение ресурсосберегающих технологий непосредственно на металлообрабатывающих заводах;

$\rightarrow$ сервис 4.0 и Smart-mapping («умная картография» и расширенная 3D-визуализация), то есть все, что связано с цифровой диагностикой и обслуживанием, а также профилактическим техобслуживанием.

Эти тенденции затрагивают не только станкостроителей Германии, но и России и всего мира. С такими задачами невозможно справиться в одиночку, необходимо создавать кластеры, различные объединения, и этим путем Россия идет так же, как и Германия, отметил Манфред Либль.
Итоги пленарного заседания форума «Технологии обработки материалов, робототехника и «Индустрия 4.0» подвел заместитель председателя Коллегии Военно-промышленной комиссии РФ Олег Бочкарёв, обозначив наиболее важные пункты повестки, наиболее активно обсуждавшиеся в процессе дискуссии.

В качестве первой задачи он отметил необходимость совершенствования законодательной базы для отрасли производства средств производства. Этот вопрос целесооб-

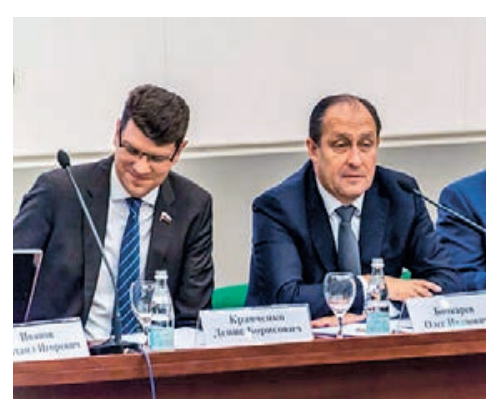
разно решать в рамках комитета по экономике и промышленности Государственной Думы РФ.

Олег Бочкарёв обозначил важную задачу для Минпромторга России - анализ реализации программ станкостроения и оценка социального и экономического эффекта, при этом оценка должна содержать конкретные цифровые показатели. Минпромторгом России проделана огромная системная работа, предприняты усилия законодательного, нормативно-правового и финансового характера. Результат подвергается экспертной критике. «В сопоставлении с объемом потраченных ресурсов результат не устраивает, - сказал Олег Бочкарёв. Минпромторг - открытая к этому процессу структура, но хотелось бы говорить о конкретном результате и эффекте». Это должно стать предметом профессионального разговора.

Третья обозначенная тема - это бизнес-модель развития отрасли. На практике можно наблюдать, что идет торможение бизнеса. Все принимают базовую модель отрасли, что все компании частные, которые занимаются разработкой и производством станкостроительной продукции. Сегодня бизнес поднимает вопрос о нехватке оборотных средств. Необходимо изучать эту ситуацию и искать решение.

Четвертая тема, относящаяся к Минпромторгу России, - перезапуск комиссии по определению наличия отечественных производителей станков. В рамках форума упоминались Постановления Правительства РФ № 9 и № 239, но этому инструменту недостает гласности. Проблема вызывает беспокойство, поскольку в Коллегию ВПК снова стали приходить жалобы на то, что российские станки не приобретаются.

Пятая тема - задача для Ассоциации «Станкоинструмент» - анализ результатов применения и использования отечественных станков. Нужна обратная связь от потребителей: надежность, коэффициент использования, съем готовых изделий, про- 
стои, качество, ремонт, сервис. Сегодня эти вопросы возникают в том контексте, что правительство «продавило» покупку отечественных станков, потребители их взяли, а они плохо работают. В терминах «хорошо работают» и «Плохо работают» такие вопросы, конечно, не могут обсуждаться. Нужна профессиональная оценка,

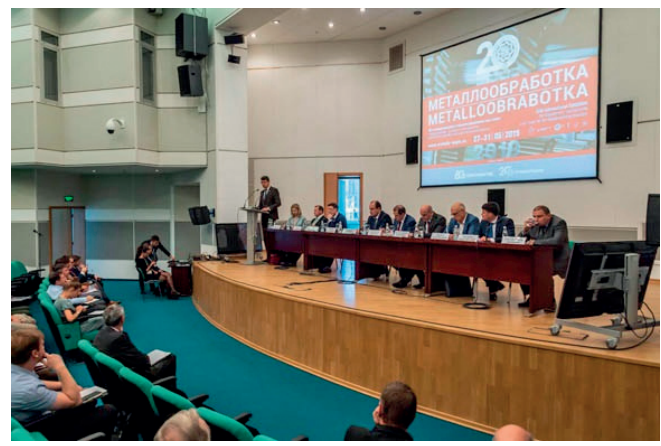
дически, а создают консорциумы и выступают на рынке в качестве системного участника, не забрасывают друг друга жалобами в различные инстанции, а договариваются о взаимодействии.

Следующий этап - через два-три года - это уже обмен акциями и выход на нормальные акционерные общества с понятной системой единонаи Ассоциация должна предоставить информацию о том, как работают станки, которые закупила наша промышленность.

Шестая тема также относится к Ассоциации «Станкоинструмент». Поскольку на выходе новый закон о СПИК 2.0 (пакет правительственных законопроектов с поправками регулирования специальных инвестиционных контрактов), который подготовлен в Минпромторге России, задача Ассоциации организовать разъяснительную, методологическую работу по внедрению этих механизмов. В законе появится много новаций. Важно, чтобы промышленность как минимум знала об этих новых инструментах, чтобы тема была профессионально «отрефлексирована», и не в категориях «плохо/хорошо, нравится/не нравится, легко/трудно», что не позволяет ориентироваться в существующей обстановке.

Седьмой вопрос - количество торговых площадок. Если, как утверждают выступавшие, их больше 60 , то это совершенно неправильно. Задача Ассоциации «Станкоинструмент» - изучить данную проблему, понять, как сложилось такое положение дел. Целесообразно начать диалог с антимонопольной службой, с Минэкономразвития, поскольку профессионализм площадок, контроль за тем, что и как они делают - это очень важно.

Восьмая тема также относится к сфере Ассоциации «Станкоинструмент». Пришло время изучить вопрос о системном взаимодействии участников рынка. Еще по итогам прошлого форума было озвучено, что 450 предприятий являются субъектами бизнеса в станкостроении. Это очень много, пора заняться переводом количества в качество. В этой связи Олег Бочкарёв поставил задачу перед Ассоциацией проанализировать бизнес-поведение на рынке такого большого количества участников и начать обсуждение вопроса интеграции в холдинги, корпорации и через два-три года прийти к тому, чтобы на рынке было максимум 10-15 крупных игроков. Иначе усилия по помощи предприятиям будут распылены. До государственной помощи будут «добегать» только максимально крепкие в административном и финансовом плане компании. На примере того, как это происходит в IT-отрасли - компании объединяются не юричалия, которая должна быть в бизнесе. Олег Бочкарёв обратился с просьбой к Ассоциации - в течение года заниматься этим вопросом. Хотя это задача не из области техники, а из сферы бизнеса, но актуальность ее решения назрела.

Девятый вопрос - развитие технологий производства комплектующих. Не может устраивать ситуация, когда станок считается российским, но значительная часть его российской не является. И хотя работа ведется в правильном направлении, можно упомянуть Постановление Правительства № 719, но нужен результат. Нужна детальная аналитика, поскольку всегда речь шла о том, что отечественное станкостроение только тогда имеет силу и основу, когда и комплектующие также производятся в России, особенно с высокой добавленной стоимостью. При этом должно существовать максимум два-три поставщика на рынке.

Десятый вопрос касается цифровизации. Ситуацию следует проанализировать, а затем уже на площадке Ассоциации «Станкоинструмент» предметно обсудить цифровизацию отрасли. Это охватывает управление кооперацией, бизнес-взаимодействие на рынке, сокращение сроков выполнения заказов, качество станков, которые мы делаем, информацию о жизненном цикле, и естественно, экономику, бизнес-результат.

Одиннадцатый пункт решения форума - предложение коллег из союза станкостроителей Германии изучить возможность семинара в Германии по теме «Индустрии 4.0» в области станкостроения и металлообработки. К этой работе стоит привлечь также представителей Сколково. Германия открыта к тому, чтобы поделиться своими знаниями в этой области. Есть положительный опыт коллег из других отраслей.

Олег Бочкарёв поручил президенту Ассоциации «Станкоинструмент» Георгию Самодурову подготовить соответствующее протокольное решение как часть итогового документа выставки «Металлообработка-2019». Также в этот документ должны быть включены все новации в законодательном и нормативноправовом поле, которые важны для участников рынка.

Материал подготовили Гринберг В.Е., Казанцева 0.А. Фomo www.metobr-expo.ru 
